\title{
Contribution to the biochemical characterization of the silk and structure characterization of the cocoons of the horse chestnut leaf miner Cameraria ohridella (Lepidoptera: Gracillariidae)
}

\author{
Veronika HNĚVSOVÁ ${ }^{1}$, DaLibor KODRÍK ${ }^{2,3 *}$ and FrantišeK WEYDA ${ }^{2,3}$ \\ ${ }^{1}$ Gymnasium, Jírovcova 8, 37161 České Budějovice, Czech Republic \\ ${ }^{2}$ Institute of Entomology, Biology Centre, Academy of Sciences and ${ }^{3}$ Faculty of Science, University of South Bohemia, \\ Branišovská 31, 37005 České Budějovice, Czech Republic
}

Key words. Silk, cocoon, pupal chamber, tissue of leaf mine, Cameraria ohridella, Gracillariidae, protease inhibitor, glycoprotein, electron microscopy

\begin{abstract}
This study of the proteins in the silk of the summer and winter cocoons of the horse chestnut leaf miner Cameraria ohridella revealed they can inhibit protease activity. The inhibitory activity of the summer silk was higher against both the fungal proteinase $\mathrm{K}$ and bacterial subtilisin than that of the winter silk. Also, the winter silk was more effective in inhibiting proteinase $\mathrm{K}$ than subtilisin. Further, it was demonstrated that some of the silk proteins are glycosylated probably by mannose carbohydrates. An electron microscopy study of the cocoons revealed the presence of silk fibres with different diameters in some pupal chambers.
\end{abstract}

\section{INTRODUCTION}

Lepidoptera produce silk from modified salivary glands, which are adapted for the production of huge quantities of fibrous proteins. The function and development of the silk glands are under hormonal control (Sehnal \& Akai, 1990; Kodrík \& Sehnal, 1994). Synthesized silk proteins are stored in the gland lumen as a jelly dope and converted into insoluble fibre during spinning (Fedič et al., 2002). According to current knowledge the major component of silk threads is fibroin, sometimes called heavy chain fibroin ( $\mathrm{H}$-fibroin, molecular weight $200-400 \mathrm{kDa}$ ). The H-fibroin is typically associated with two small proteins of molecular weight about $25-30 \mathrm{kDa}$ : light chain fibroin (L-fibroin; Kimura et al., 1985; Žurovec et al., 1995) and P25 glycoprotein (Couble et al., 1983; Žurovec et al., 1998b), respectively, that play a role in assembling the fibroin subunits (Inoue et al., 2000) and facilitate transport and secretion of the insoluble fibroin (Tanaka et al., 1999). The fibroin is coated with several sericin proteins, which at the common outlet cement the two silk threads into a single fibre that is spun out from the spinneret (Sehnal \& Akai, 1990). The sericins dissolve in hot alkaline water during silk reeling and the silk thread used in the textile industry is practically pure fibroin.

The above mentioned components of lepidopteran silk are associated with several additional proteins (molecular weight 5-25 kDa) (Sasaki \& Noda, 1973; Grzelak et al., 1988; Kodrík, 1992) that permeate both the fibroin core and the sericin coating. Among these are Kunitz and Kazal type protease inhibitors, which are peptides with molecular weights of 4-6 $\mathrm{kDa}$ (Nirmala et al., 2001a, b). A question arises as to the role of these inhibitors in the silk. It is assumed that the inhibitors (protease inhibitors and other silk proteins called seroins; Žurovec et al., 1998a) are involved in the protection of the cocoons against microbes and predators. In this way it is likely that the cocoons resist attack by bacteria and moulds and are not devoured by mites, insects, and other animals that are able to digest silk proteins.
Almost all the information on the functions of lepidopteran silk glands and the composition and character of the silk proteins, including the controlling genes, were obtained from two species: the silkworm Bombyx mori (Bombycidae) and the wax moth Galleria mellonella (Pyralidae). There is little or no similar information for other species of Lepidoptera (Sehnal \& Žurovec, 2004). This was one of the reasons why we focussed on another lepidopteran in this study: the horse chestnut leaf miner Cameraria ohridella (Gracillariidae). From the point of view of research on silk, this species is attractive because that it spins its cocoon within plant tissue. Feeding of the $C$. ohridella larvae inside leaves is an innovative way of consuming foliage. However, there are both advantages and disadvantages connected with feeding inside leaf mines compared to external feeding on leaves, which is the case, e.g., in B. mori (Connor \& Taverner, 1997). One such disadvantage is a lower mobility resulting in higher mortality from parasitism. A possible effective protection against environmental changes as well as against external parasitoids and fungi might be the pupal chamber, which is enclosed by a silk cocoon. The existence of this silk cocoon in C. ohridella was described by Skuhravý (1998).

C. ohridella larvae produce two types of silk cocoons: (1) Complete type is created by those last-instar larvae that produce diapausing pupae (diapausing pupae occur in a small percentage of the first generation of this species and increasing percentages of the second, third and fourth generations; the silk cocoon lines the inside of the pupal chamber fully covering the pupa; only diapausing pupae are able to overwinter). (2) Incomplete type is built by the last larval instars producing non-diapausing summer pupae (the pupal chamber contains only a thin silk cocoon consisting of substantially less material than the cocoon enclosing diapausing pupae; pupae enclosed in incomplete silk cocoons are not able to overwinter). The nature of the silk used in the construction of these two types of cocoon, the first sampled in winter (see 1 above) and designated "winter silk", and second sampled at the end of summer (see 2 above) designated "summer silk", were the subject of this study.

\footnotetext{
* Corresponding author; e-mail: kodrik@entu.cas.cz
} 
The main aim of the present study was to characterize the biochemical properties of some $C$. ohridella silk proteins, especially those that inhibit protease activity and may be involved in protection, and to describe the silk produced by the summer and winter generations of this species. These results were supplemented by electrophoretic and glycoprotein analyzes of silk proteins and a structural study of $C$. ohridella cocoons using an electron microscope.

\section{MATERIAL AND METHODS}

\section{Silk cocoons}

Fresh horse chestnut leaves containing summer cocooned pupae of the horse chestnut leaf miner $C$. ohridella were collected in the vicinity of České Budějovice (Czech Republic, $49^{\circ} \mathrm{N}$ ) in early September (for "summer silk") and fallen leaves containing winter cocooned pupae from around defoliated horse chestnut trees in December (for "winter silk"). The silk cocoons were immediately dissected from the leaves, the remaining plant tissue removed from the cocoons under a dissecting microscope and the silk stored at room temperature in microcentrifuge tubes until processed.

\section{Protein extraction}

Several dozen clean cocoons $(3 \mathrm{mg})$ were shredded and then immersed for $48 \mathrm{~h}$ either in (A) $250 \mu 10.11 \%$ trifluoroacetic acid (TFA) (Nirmala et al., 2001a) or (B) $75 \mu 110 \mathrm{mM}$ tris buffer, pH 7.0, containing $8 \mathrm{M}$ urea, $2 \%$ sodiumdodecyl sulphate (SDS) and 5\% 2-mercaptoethanol (added just before use) (Tokutake, 1980). The insoluble material was removed and the crude extract divided into aliquots for testing for the presence of protease inhibitory activity (buffer A) and the electrophoretic analysis (buffer B).

\section{Determination of protease inhibitory activity}

Proteinase K (fungal protease from the ascomycote Tritirachium album) and subtilisin (bacterial protease from Bacillus subtilis) were used as the target enzymes of the protease inhibitors extracted from $C$. ohridella silk. The inhibition was measured using the azocasein method according to the Roche Company protocol modified for the microplate ELISA photometric reader. Typically, the $0.11 \%$ TFA silk extract $(20 \mu 1)$ was serially diluted in $0.11 \%$ TFA and subsequently $0.4 \%$ resorufin casein in water, $0.2 \mathrm{M}$ tris, $0.02 \mathrm{M}$ calcium chloride and $50 \mathrm{ng}$ of enzyme (each component in $20 \mu \mathrm{l}$ ) were added. Protein concentration in the analysed silk extract was determined using the bicinchoninic acid (BCA) photometric method (Stoscheck, 1990), a UV 1601 Shimadzu spectrophotometer, a commercial kit (Sigma) and bovine serum albumin (BSA) as the standard. Appropriate negative controls without the enzyme and positive controls without the inhibitor (silk extract) were assayed simultaneously. The reaction mixtures were shaken and incubated at $37^{\circ} \mathrm{C}$ for $1 \mathrm{~h}$, then $240 \mu \mathrm{l}$ of blocking solution ( $5 \%$ trichloroacetic acid) was added and $10 \mathrm{~min}$ later the samples were centrifuged. Aliquots of $300 \mu \mathrm{l}$ of the supernatant were placed in a 96-well microplate for optical density measurements at $490 \mathrm{~nm}$ (Spectra Max340 PC reader, Molecular Devices). The difference in absorbance between the positive and the negative control was taken as $100 \%$ protease activity. An increase in this activity in the serially diluted silk extracts (containing a smaller amount of the inhibitor) indicated that the respective sample contained a protease inhibitor. The level of inhibition was expressed in terms of Dm values (protein amount causing 50\% inhibition - median effect) (Chou \& Chou, 1987).

\section{Electrophoretic and glycoprotein analyses of the silk proteins}

Thirty $\mu \mathrm{l}$ aliquots of the silk extract (urea containing B buffer - see above) were analysed by SDS-PAGE (sodiumdodecyl sul-

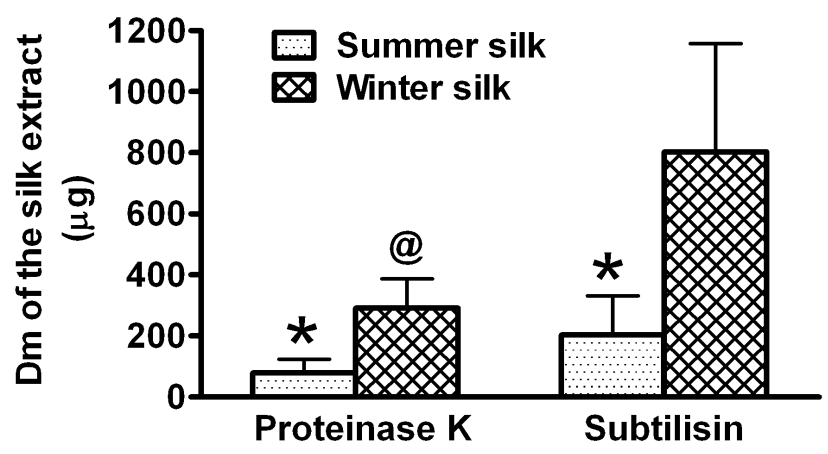

Fig. 1. Inhibitory effect of extracts of $C$. ohridella summer and winter silk on the activity of proteinase $\mathrm{K}$ and subtilisin. The results are expressed in Dm (mean $\pm \mathrm{SD}, \mathrm{n}=4)$ - the dose causing a $50 \%$ inhibition. Statistics - Student's t-test: significant differences at the $5 \%$ level between the summer and winter silk for the specific enzyme are labelled by asterisks, and between proteinase $\mathrm{K}$ and subtilisin for winter silk by @. No significant difference between the enzymes was recorded for summer silk.

phate - polyacrylamide gel electrophoresis) on a $15 \%$ gel according to Laemmli (1970). The proteins were visualised by staining with silver nitrate (Kirkeby et al., 1993) or electroblotted on a nitrocellulose membrane according to Towbin et al. (1979) and probed with lectins (Grubhoffer et al., 1990) concanavalin A (ConA) $(50 \mathrm{ng} / \mathrm{ml})$, wheat germ agglutinin (WGA) $(50 \mathrm{ng} / \mathrm{ml})$ and Phaseolus vulgaris erythroagglutinin (PHA-E) $(200 \mathrm{ng} / \mathrm{ml})$, respectively, to demonstrate the presence of sugar component(s) in their molecules. The membrane with biotinylated lectins was incubated with horseradish peroxidise streptavidin (Vector Laboratories) diluted 1:500 and the complex visualized by reaction with diaminobenzidine.

\section{Electron microscopy}

For conventional scanning electron microscopy, a dry whole pupal chamber (with upper leaf tissue covering the chamber removed, so that the main oval-like silk cocoon layer was exposed) was glued on an aluminium holder, sputter-coated by gold and observed and photographed using a Jeol 6300 scanning electron microscope.

\section{Data presentation and statistical analysis}

The data presented in Fig. 1 were plotted using the graphic program Prism (GraphPad Software, version 5.0, San Diego, CA, USA). The bars represent the mean of measurements \pm SD. Each Dm was calculated as a mean of 4 parallel measurements and each of the measurements consisted of 8 different sample doses from the cocoons. The significance of the results was evaluated using a standard Student's t-test with a 5\% significance level.

\section{RESULTS AND DISCUSSION}

The first series of experiments using the azocasein test and two proteases, proteinase $\mathrm{K}$ and subtilisin, focussed on a comparison of the inhibitory activity of $0.11 \%$ TFA extracts isolated from the summer and winter $C$. ohridella silk (Fig. 1). The purity of the protease inhibitors extracted by the TFA buffer from the silk is acceptable (Nirmala et al., 2001a). The results revealed that the extract of summer silk was about 3.7 fold more effective in inhibiting proteinase $\mathrm{K}$ and about 4.0 fold more effective in inhibiting subtilisin than the extract of winter silk (the smaller the amount of the inhibitor needed for the inhibitory effect, the greater its inhibitory activity). Both differences were 


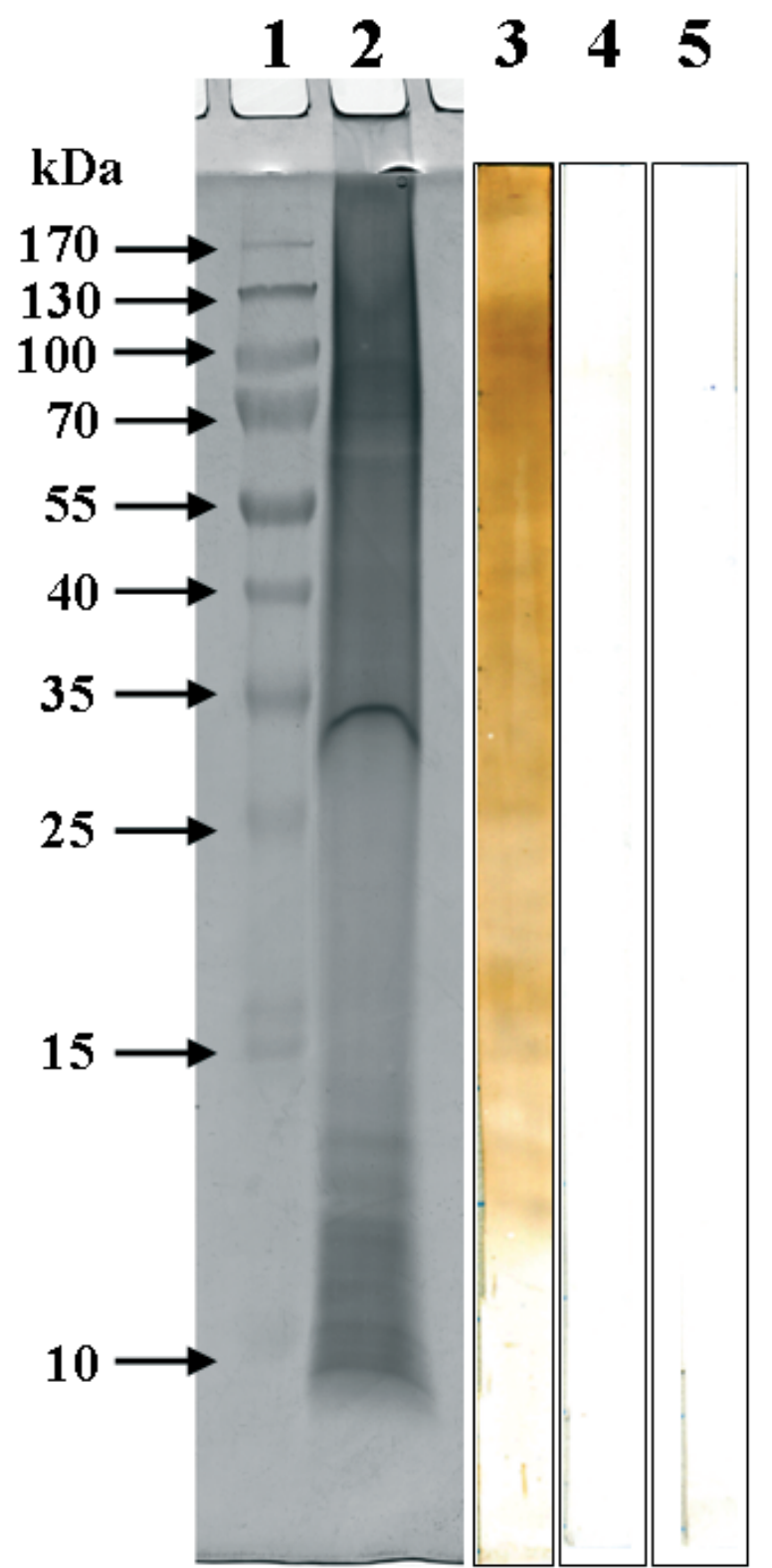

Fig. 2. Electrophoretic analysis and detection of glycosylated proteins in C. ohridella silk. Lines 1 and 2 represent the separation of molecular weight standards and silk proteins on $15 \%$ SDS-PAGE gel stained with silver nitrate. Lines 3-5 represent the silk proteins electroblotted on a nitrocellulose membrane, probed with lectins and visualized by diaminobenzidine (for details see Materials and methods). Line 1: molecular weight standards (Fermentas - Thermo Scientific); line 2: C. ohridella winter silk dissolved in the urea buffer; line 3: the silk reaction with concanavalin A; line 4: the silk reaction with wheat germ agglutinin; line 5: the silk reaction with Phaseolus vulgaris erythroagglutinin.

statistically significant at the $5 \%$ level. Moreover, significant difference was recorded for the extract of winter silk in its inhibition of the tested enzymes: inhibition of fungal protease $\mathrm{K}$ was about 2.8 fold greater than that of bacterial subtilisin. On the other hand the inhibition of both enzymes by the extract of summer silk was not statistically different, which suggests that this silk was equally effective at inhibiting both enzymes. Protease inhibitors are present in the silk (molecular weights 4-6 $\mathrm{kDa}$ ) produced by $G$. mellonella (Nirmala et al., 2001a) and $B$.
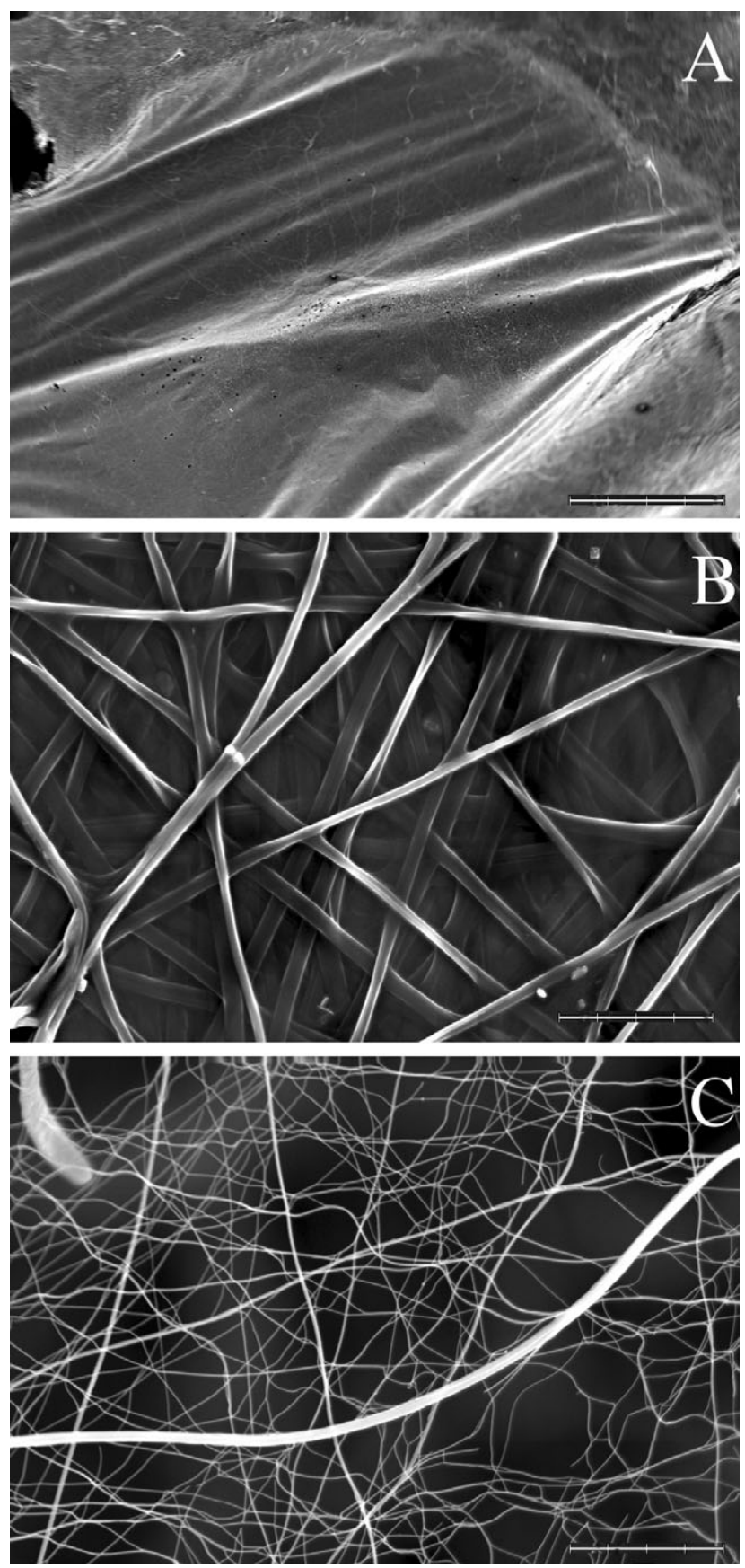

Fig. 3. Scanning electron micrographs of a winter pupal chamber containing a silk cocoon of $C$. ohridella. A - general view of a pupal chamber (leaf tissue above mine removed) covered by an oval-like silk cocoon layer; B - detailed view of typical silk cocoon consisting of silk fibres of similar diameter; $\mathrm{C}$ - atypical silk cocoon consisting of silk fibres of various diameters. Scales: $100 \mu \mathrm{m}(\mathrm{A})$ and $1 \mu \mathrm{m}(\mathrm{B}, \mathrm{C})$.

mori (Nirmala et al., 2001b), and are thought to be present in all lepidopteran silk, where they serve to protect the cocoon and developing pupa against microbial degradation and from being eaten by animals. One of the protease inhibitors isolated from Galleria silk, called GmSPI2, which has a unique and relatively simple structure (only 36 amino acid residues) and was produced by the expression vector Pichia pastoris, inhibits the activity of various proteases (Kludkiewicz et al., 2005). It is assumed that the seroin silk proteins (molecular weight about 
8-16 kDa) identified in both the above mentioned species (Žurovec et al., 1998a; Nirmala et al., 2001b), are also protease inhibitors. In addition, the Galleria $16 \mathrm{kDa}$ seroin generates two further glycosylated products of molecular weight 22.5 and 23 $\mathrm{kDa}$, respectively (Žurovec et al., 1998a).

The differences in the inhibitory activity of extracts of $C$. ohridella summer and winter silk against the tested proteases shown in Fig. 1 suggest that the protective strategies of this moth change during the course of a year. It is possible that the higher inhibitory activity of summer silk reflects the necessity of a more intensive protection of the cocoon against microbes (and predatory insects) during this period than in winter. The more intensive protection of winter silk against fungal proteinase $\mathrm{K}$ than bacterial subtilisin might be associated with $C$. ohridella overwintering in fallen horse chestnut leaves on land, where fungal activity might be greater than bacterial activity. In the absence of supportive data this hypothesis, however, needs to be tested.

In the second series of experiments silk proteins soluble in the urea buffer were studied. This buffer is capable of dissolving all silk proteins with the exception of $\mathrm{H}$-fibroin, the core silk protein. This experiment revealed a number of $C$. ohridella silk proteins, which were separated and visualized using SDS-PAGE (Fig. 2). These proteins had molecular weights greater than 10 $\mathrm{kDa}$. It is probable that the general pattern of proteins in $C$. ohridella silk is similar to that of the silk of other Lepidoptera, i.e., fibroin - sericins - "small" proteins. Also the presence of proteins with molecular weights between $10-30 \mathrm{kDa}$, as shown in Fig. 2, is similar to that recorded for both B. mori and G. mellonella (Gamo et al., 1977; Grzelak et al., 1988; Kodrík, 1992). Despite the fact that the function of fibroin and sericins in insect silk has been known for a long time, the roles of the "small" molecular weight proteins were only partially elucidated relatively recently using molecular biology techniques. The L-fibroin and P25 protein play a role in assembling and spinning the fibroin molecules: the necessity of the disulphide linkage between L-fibroin and $\mathrm{H}$-fibroin for their secretion was revealed by studies on $B$. mori mutants with defects in these components (Takei et al., 1987). The P25 is suggested to act as chaperone that facilitates the transport and secretion of $\mathrm{H}$-fibroin (Tanaka et al., 1999). Similarly, in G. mellonella the P25 proteins are supposed to play an analogous role in silk formation. Žurovec et al. (1998b) demonstrate that the 29 and $30 \mathrm{kDa}$ Galleria silk proteins are derived from a single gene designated $\mathrm{P} 25$ that produces a protein of about $25 \mathrm{kDa}$ and that the 29 and $30 \mathrm{kDa}$ forms are derived from this primary translation product by different glycosylation.

As there are some indications that the proteins extracted from C. ohridella silk could also contain glycosylation sites, they were probed with several lectins (Fig. 2). The presence of sugar moieties was shown by their reaction with concanavalin A (Fig. 2 , line 3), which indicates the presence of mannose-rich carbohydrates in molecules. There were no reactions with the other lectins used in this study (Fig. 2, lines 4-5). Thus, as in the silk of $B$. mori and G. mellonella, there are also glycoproteins in $C$. ohridella silk, however, their role is not understood.

The biochemical characterization of $C$. ohridella silk was supplemented by an electron microscope study, which revealed some interesting features of the cocoon (Fig. 3). The upper layer of a typical silk cocoon (Fig. 3A) is composed of irregularly arranged silk fibres of more or less identical diameter (Fig. 3B) glued together presumably by sericin. The cocoons were mostly oval in shape and their fibres were approximately $750 \mathrm{~nm}$ in diameter. In contrast, Fig. 3C depicts an atypically formed upper layer that is constructed mostly of curled silk fibres of various diameters. This type of fibre organization is very rare in
C. ohridella cocoons. The fibre diameter is limited by the diameter of a spinneret, which cannot be substantially changed by the larvae. We have no explanation of how C. ohridella is able to change the form of the silk or why.

In summary, the results demonstrate that $C$. ohridella silk can inhibit protease activity. The summer silk more effectively inhibited both the activity of fungal proteinase $\mathrm{K}$ and bacterial subtilisin than the winter silk. Moreover, the winter silk more effectively inhibited the activity of proteinase $\mathrm{K}$ than subtilisin. The use of a set of lectins revealed that some of the silk proteins are glycosylated, probably by mannose carbohydrates. The electron microscopy study revealed the arrangement and diameter of the silk fibres both in typical and rare atypical cocoons. To our knowledge this is the first study to report data on this leaf miner's silk, however, further work is needed to fully elucidate the implications of this study.

ACKNOWLEDGEMENTS. This study was supported by a project of the Academy of Sciences of the Czech Republic - Open Science CZ.1.07/2.3.00/09.0034 No. 1.33/3 (VH), grant No. 2B06005 from the Ministry of Education, Youth and Sports of the Czech Republic, grant No. P502/10/2382 from the Czech Science Foundation, and the Institute of Entomology project No. Z50070508 funded by the Academy of Sciences of the Czech Republic. The authors thank L. Grubhoffer (University of South Bohemia) for kindly providing the lectins used in this study and N. Krishnan (Oregon State University) for critical reading of the manuscript.

\section{REFERENCES}

Chоu J. \& Chou T.C. 1987: Dose-Effect Analysis with Microcomputers. Biosoft, Cambridge, UK, 93 pp.

CONNOR E.F. \& TAVERnER M.P. 1997: The evolution and adaptive significance of the leaf-mining habit. Oikos 79: 6-25.

Couble P., Moine A., Garel A. \& Prudhomme J.C. 1983: Developmental variations of a nonfibroin mRNA of Bombyx mori silkgland, encoding for a low-molecular-weight silk protein. Dev. Biol. 97: 398-407.

Fedič R., Žurovec M. \& Sehnal F. 2002: The silk of Lepidoptera. J. Insect Biotech. Sericol. 71: 1-15.

GAmo T., Inouchi T. \& Laufer H. 1977: Polypeptides of fibroin and sericin secreted from the different sections of the silk gland in Bombyx mori. Insect Biochem. 7: 285-295.

Grubhoffer L., Guirakhoo F., Heinz F.X. \& Kunz C. 1990: Interaction of tick-borne encephalitis virus protein E with labelled lectins. In Kocourek J. \& Freed. D.L. (eds): Lectins: Biology, Biochemistry, Clinical Biochemistry. Vol. 7. Sigma Chemical Company, Saint Louis, pp. 313-319.

Grzelak K., Couble P., Garel A. \& Kludkiewicz B. 1988: Low molecular weight silk proteins in Galleria mellonella. Insect Biochem. 18: 223-228.

Inoue S., Tanaka K., Arisaka F., Kimura S. Оhmoto K. \& Mizuno S. 2000: Silk fibroin of Bombyx mori is secreted, assembling a high molecular mass elementary unit consisting of H-chain, L-chain, and P-25, with a 6:6:1 molar ratio. $J$. Biol. Chem. 275: 40517-40528.

Kimura K., Oyama F., Ueda H., Mizuno S. \& Shimura K. 1985: Molecular cloning of the fibroin light chain complementary DNA and its use in the study of the expression of the light chain gene in the posterior silk gland of Bombyx mori. Experientia 41: 1167-1171.

Kirkeby S., Moe D. \& Bog-Hansen T.C. 1993: The silver staining procedure of sodium dodecyl sulphate-gels may be accelerated by shortening fixation time. Electrophoresis 14: $51-55$. 
Kludkiewicz B., Kodrík D., Grzelak K., Xavier N. \& Sehnal F. 2005: Structurally unique recombinant Kazal-type proteinase inhibitor retains activity when terminally extended and glycosylated. Protein Expres. Purif. 43: 94-102.

KODRÍK D. 1992: Small protein components of the cocoons in Galleria mellonella (Lepidoptera, Pyralidae) and Bombyx mori (Lepidoptera, Bombycidae). Acta Entomol. Bohemoslov. 89: $269-274$

KodRíK D. \& SeHnal F. 1994: Juvenile hormone counteracts the action of ecdysterone on silk glands of Galleria mellonella L. (Lepidoptera: Pyralidae). Int. J. Insect Morphol. Embryol. 23: 39-56.

LAEMMLI U.K. 1970: Cleavage of structural proteins during the assembly of the head of bacteriophage T4. Nature 227: $680-685$.

Nirmala X., Kodrík D., Žurovec M. \& Sehnal F. 2001a: Insect silk contains both a Kunitz-type and a unique Kazal-type proteinase inhibitors. Eur. J. Biochem. 268: 2064-2073.

Nirmala X., Mita K., Vanisree V., Žurovec M. \& Sehnal F. 2001b: Identification of four small molecular mass proteins in the silk of Bombyx mori. Insect Mol. Biol. 10: 437-445.

SASAKI T. \& Noda H. 1973: Studies on silk fibroin of Bombyx mori directly extracted from the silk gland. I. Molecular weight determination in guanidine hydrochloride or urea solutions. Biochim. Biophys. Acta 310: 76-90.

Sehnal F. \& AKai H. 1990: Insects silk glands: their types, development and function, and effects of environmental factors and morphogenetic hormones on them. Int. J. Insect Morphol. Embryol. 19: 79-132.

Sehnal F. \& Žurovec M. 2004: Construction of silk fiber core in Lepidoptera. Biomacromolecules 5: 666-674.
SkuHravÝ V. 1998: On the leaf mining moth Cameraria ohridella Desch. \& Dim. (Lep., Lithocolletidae) attacking Aesculus hippocastanum L. in the Czech Republic. Anz. Schadlingsk. Pflanzensch. Umweltsch. 71: 81-84.

Stoschecк C.M. 1990: Quantitation of proteins. Methods Enzymol. 182: 50-68.

Takei F., Kikuchi Y., Kikuchi A., Mizuno S. \& Shimura K. 1987: Further evidence for importance of the subunit combination of silk fibroin in its efficient secretion from the posterior silk gland cells. J. Cell Biol. 105: 175-180.

Tanaka K., Inoue S. \& Mizuno S. 1999: Hydrophobic interaction of P25, containing Asn-linked oligosaccharide chains, with the H-L complex of silk fibroin produced by Bombyx mori. Insect Biochem. Mol. Biol. 29: 269-276.

TOKUTAKE S. 1980: Isolation of the smallest component of silk protein. Biochem. J. 187: 413-417.

Towbin H., Staehlin T. \& Gordon J. 1979: Electrophoretic transfer of proteins from polyacrylamide gels to nitrocellulose sheets: Procedure and some applications. Proc. Natl. Acad. Sci. U. S. A. 76: 4350-4354.

Žurovec M., VašKová M., Kodrík D., Sehnal F. \& Kumaran A.K. 1995: Light-chain fibroin of Galleria mellonella L. Mol. Gen. Genet. 247: 1-6.

Žurovec M., Yang C., Kodrík D. \& Sehnal F. 1998a: Identification of a novel type of silk protein and regulation of its expression. J. Biol. Chem. 273: 15423-15428.

Žurovec M., Kodrík D., Yang C., Sehnal F. \& Scheller K. 1998b: P25 component of Galleria silk. Mol. Gen. Genet. 257: 264-270.

Received April 28, 2011; revised and accepted July 26, 2011 